\title{
A Potential Parameter for A Non-Darcy Form of Two-Phase Flow Behaviour, Compressibility Related
}

\author{
Bashir Busahmin $^{1 *}$ and Brij Maini \\ ${ }^{1}$ Petroleum and Chemical Engineering, Universiti Teknologi Brunei, Brunei Darussalam. \\ ${ }^{2}$ Chemical and Petroleum engineering, University of Calgary, Canada. \\ ${ }^{*}$ Corresponding author: bashir.abusahmin@utb.edu.bn
}

\begin{abstract}
Numerous scientists did their studies and conducted various laboratory experiments related to a non-Darcy behavior of a two-phase flow for the past thirty years, and made an effort to clarify the behavior. Non-Darcy flow behavior, phenomena occurred in primary recovery method of reservoirs that have an API degree gravity of less than 20. It was confirmed that it results in greater production. The compressibility of foam fits to be the one of the general fundamental factor that directs the lifetime of a non-Darcy form of two phase flow behavior or also is known as the foamy oil. In the process of usual drive depletion, foamy oil featured of low production GOR and high daily production rate. Foamy oil is more compressible than conventional solution gas due to the oil that gas dispersed in it; as a result, oil formation volume factor is much higher than that in conventional oil. This paper represents a laboratory data followed by some of the analysis related to the properties of non-Darcy form of two phase flow and that is the compressibility parameter. The experimental results showed that at different saturation pressures and at a room temperature, the trends fit the expected behavior above the saturation pressures. Moreover, the measurements of live oil compressibility were also attempted below the saturation pressures. It was concluded that other properties such as the viscosity is added a significant effect rather than compressibility in the behavior of what so called foamy oil compared to the presence or absence of asphaltenes and other polar oil components.
\end{abstract}

Keywords: Capillary number; Depletion test; Foamy oil property; Solution gas drive. 


\section{Introduction}

Over almost the last three decades Foamy oil behavior has been studied by different researchers and scholars Indeed, foamy oil expression typically is indirect to what is known as heavy oil at the reservoir conditions somewhere it was found that crude oil is more viscous than refined mineral oil [1]. Further experimental studies conducted by Busahmin and Maini e.g. related to foam stability and came up with that the non-Darcy of two phase flow performance is adversely impacted by non-produced gas-oil-ratio, however high compressibility makes the system highly nonlinear and created a time dependent model to predict volumes entrained and found the compressibility of foamy oil [2]. Much of the engineering aspects that is involved in the development and exploration of reservoirs worldwide depends on physical properties of fluid especially compressibility and density of heavy oil. The process parameter influence the solution gas performance, and hence they need to optimize using hybrid evolutionary techniques [3-6].

The recent studies analysed oil recovery behavior of crude oil and the mineral oil under solution gas drive under different depletion rates and compressibility [7]. These studies reported about the compressibility of the gas-dispersed oil in it is greater than the oil containing dissolved gas. Few studies carried out research studies to estimate compressibility of foamy oil used simple model correlations [8]. It was suggested by Busahmin and Maini [9] where the drive energy to oil flow dramatically reduces the fractional flow of gas. Foamy oil viscosity, compressibility and permeability were presented by Zhang et al. [10]. In the phase of production, the average capillary number shows large fluctuations. These fluctuations result from changes between the constant recovery of gas and the recovery of non-Darcy two-phase flow behaviour [11]. Production of non-thermal technique has developed over many years; Figure 2 represents an example of heavy oil that features high viscous reservoir with a net pay. It is a feasible technique for oil, water, gas and sand production along with in a primary (non-thermal) recovery process, a practical reservoir example of that is in Lloydminster- Canada [12].

\section{Experimental setup}

\section{A. Determination of Dead Oil Compressibility}

Dead oil compressibility for both refined crude and mineral oil were measured using the densitometer (Paar DMA 45) and the schematic of the measurement is shown in Figure 1. Initially the dead oil was pumped into the densitometer by using the transfer vessel equipped with mini pump and then the oil was compressed at different absolute pressures and the densities were monitored at different pressures.

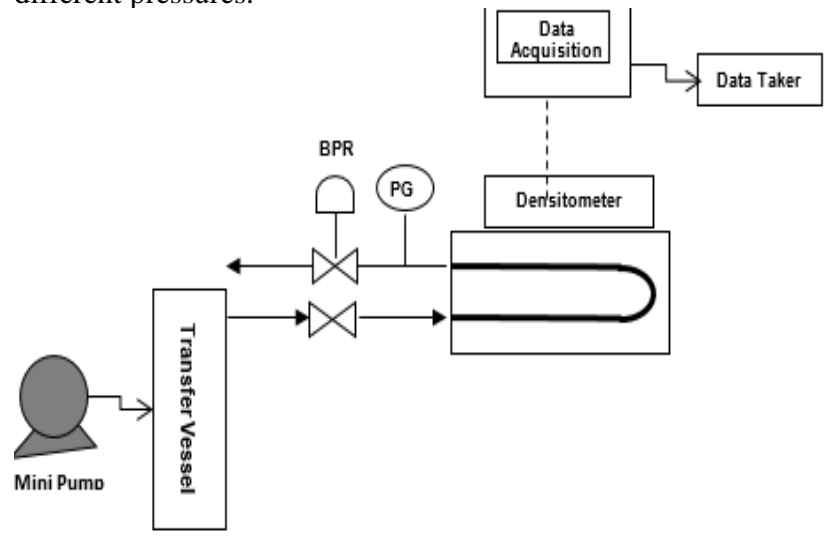

Fig. 1. The Compressibility Set-up at Room Temperature

\section{B. Determination of Live oil compressibility}

The compressibility of the live oil was measured using the same experimental set-up following the same procedure followed to determine the compressibility of dead oil. The compressibility of live oil was determined at different saturation pressures and constant room temperature, $25^{\circ} \mathrm{C}$.

After placing the live oil in the densitometer and recording a steady state value above the desired saturation pressure, immediately the globe valve between the densitometer and the oil supply transfer vessel was closed off. Then, the valve to the backpressure regulator (BPR) was opened with its system pressure set at the saturation pressure and the corresponding density is recorded. Then, by reducing the system pressure to a lower pressure which is below the saturation pressure of oil, the corresponding density was also measured. Subsequently the pressure was steadily further reduced and the density variations at each pressure were recorded. This procedure is repeated until the density readings became unstable due to gas evolution.

Table 1: Experimental fluid data for mineral and crude oils

\begin{tabular}{|l|c|c|c|c|}
\hline \multicolumn{1}{|c|}{ Parameter } & $\begin{array}{c}\text { Mineral } \\
\text { oil }\end{array}$ & $\begin{array}{c}\text { Crude } \\
\text { oil }\end{array}$ & $\begin{array}{c}\text { Saturated } \\
\text { mineral oil }\end{array}$ & $\begin{array}{c}\text { Saturated } \\
\text { crude oil }\end{array}$ \\
\hline $\begin{array}{l}\text { saturation } \\
\text { pressure[psi] }\end{array}$ & 8 & N/A & 500 & 500 \\
\hline $\begin{array}{l}\text { viscosity @ } 23^{\circ} \mathrm{C} \\
\text { [m.Pa..s] }\end{array}$ & 1583 & 2608 & 1080 & 1300 \\
\hline $\begin{array}{l}\text { liquid Phase } \\
\text { compressibility [psi }{ }^{-1}, \\
\left.10^{6}\right]\end{array}$ & 6.80 & 6.90 & 4.52 & 4.37 \\
\hline $\begin{array}{l}\text { solution gas oil ratio } \\
{\left[\mathrm{cm}^{3} / \mathrm{cm}^{3}\right]}\end{array}$ & N/A & N/A & 9.1 & 10 \\
\hline
\end{tabular}

Table 2: Compressibility data for methane saturated mineral oil

\begin{tabular}{|c|c|c|c|c|}
\hline $\begin{array}{c}\text { Pressure, } \\
\mathrm{psi}\end{array}$ & $\begin{array}{c}\text { Density, } \\
\mathrm{kg} / \mathrm{m}^{3}\end{array}$ & $\begin{array}{c}\text { Pressure } \\
\text { difference, } \Delta \mathrm{p}\end{array}$ & $\begin{array}{c}\text { Density, } \\
\mathrm{g} / \mathrm{cm}^{3}\end{array}$ & $\begin{array}{c}\text { Compressibility, } \\
10^{6} \mathrm{psi}^{-1}\end{array}$ \\
\hline 500 & 890.6527 & 20 & 0.0785 & 4.40688 \\
\hline 520 & 890.7312 & 20 & 0.0416 & 2.33516 \\
\hline 540 & 890.7728 & 20 & 0.1015 & 5.69730 \\
\hline 560 & 890.8743 & 20 & 0.0832 & 4.66957 \\
\hline 580 & 890.9575 & 20 & 0.0785 & 4.40537 \\
\hline 600 & 891.0360 & 20 & 0.0831 & 4.66311 \\
\hline 620 & 891.1191 & 20 & 0.0877 & 4.92078 \\
\hline 640 & 891.2068 & 20 & 0.0831 & 4.66222 \\
\hline 660 & 891.2899 & 20 & 0.0785 & 4.40373 \\
\hline 680 & 891.3684 & 20 & 0.0878 & 4.92501 \\
\hline 700 & 891.4562 & 20 & 0.0877 & 4.91892 \\
\hline 720 & 891.5439 & 20 & 0.0739 & 4.14450 \\
\hline 740 & 891.6178 & 20 & 0.0831 & 4.66007 \\
\hline 760 & 891.7009 & 20 & 0.0831 & 4.65963 \\
\hline 780 & 891.7840 & 20 & 0.0669 & 3.74474 \\
\hline 800 & 891.8507 & 20 & 0.0810 & 4.54168 \\
\hline 820 & 891.9318 & 20 & 0.0877 & 4.91630 \\
\hline 840 & 892.0195 & 20 & 0.0877 & 4.91581 \\
\hline 860 & 892.1072 & 20 & 0.0785 & 4.39970 \\
\hline 880 & 892.1857 & 20 & 0.0785 & 4.39931 \\
\hline 900 & 892.2642 & 20 & 0.0785 & 4.39892 \\
\hline
\end{tabular}

Table 3: Compressibility Data for methane saturated crude oil as a function of density and pressure

\begin{tabular}{|c|c|c|c|c|}
\hline $\begin{array}{c}\text { Pressure, } \\
\mathrm{psi}\end{array}$ & $\begin{array}{c}\text { Density, } \\
\mathrm{kg} / \mathrm{m}^{3}\end{array}$ & $\begin{array}{c}\text { Pressure } \\
\text { difference, } \Delta \mathrm{p}\end{array}$ & $\begin{array}{c}\text { Density, } \\
{\mathrm{g} / \mathrm{cm}^{3}}^{3}\end{array}$ & $\begin{array}{c}\text { Compressibility, } \\
10^{6} \mathrm{psi}^{-1}\end{array}$ \\
\hline 500 & 927.9647 & 20 & 0.0461 & 2.48393 \\
\hline 520 & 928.0108 & 20 & 0.0830 & 4.47193 \\
\hline 540 & 928.0938 & 20 & 0.0645 & 3.47486 \\
\hline 560 & 928.1583 & 20 & 0.1244 & 6.70144 \\
\hline 580 & 928.2827 & 20 & 0.0875 & 4.71300 \\
\hline 600 & 928.3702 & 20 & 0.0737 & 3.96932 \\
\hline 620 & 928.4439 & 20 & 0.0737 & 3.96901 \\
\hline 640 & 928.5176 & 20 & 0.1014 & 5.46032 \\
\hline 660 & 928.6190 & 20 & 0.0783 & 4.21594 \\
\hline
\end{tabular}




\begin{tabular}{|l|l|l|l|l|}
\hline 680 & 928.6973 & 20 & 0.1014 & 5.45926 \\
\hline 700 & 928.7987 & 20 & 0.0967 & 5.20565 \\
\hline 720 & 928.8954 & 20 & 0.0553 & 2.97665 \\
\hline 740 & 928.9507 & 20 & 0.0830 & 4.46741 \\
\hline 760 & 929.0337 & 20 & 0.0691 & 3.71892 \\
\hline 780 & 929.1028 & 20 & 0.0829 & 4.46129 \\
\hline 800 & 929.1857 & 20 & 0.0829 & 4.46090 \\
\hline 820 & 929.2686 & 20 & 0.0783 & 4.21299 \\
\hline 840 & 929.3469 & 20 & 0.0784 & 4.21802 \\
\hline 860 & 929.4253 & 20 & 0.0783 & 4.21228 \\
\hline 880 & 929.5036 & 20 & 0.0829 & 4.45937 \\
\hline 900 & 929.5865 & 20 & 0.0829 & 4.45919 \\
\hline
\end{tabular}

Table 3: Compressibility Data for ethane saturated mineral oil below the saturation pressure, $270 \mathrm{psi}$

\begin{tabular}{|c|c|c|c|c|}
\hline $\begin{array}{c}\text { Pressure, } \\
\mathrm{psi}\end{array}$ & $\begin{array}{c}\text { Density, } \\
\mathrm{kg} / \mathrm{m}^{3}\end{array}$ & $\begin{array}{c}\text { Pressure } \\
\text { difference, } \Delta \mathrm{p}\end{array}$ & $\begin{array}{c}\text { Density, } \\
\mathrm{g} / \mathrm{cm}^{3}\end{array}$ & $\begin{array}{c}\text { Compressibility, } \\
10^{6} \mathrm{psi}^{-1}\end{array}$ \\
\hline 60 & 860.6418 & 20 & 0.8606 & 2.48393 \\
\hline 80 & 860.7436 & 20 & 0.8607 & 4.47193 \\
\hline 100 & 860.8361 & 20 & 0.8608 & 3.47486 \\
\hline 120 & 860.9286 & 20 & 0.8609 & 6.70144 \\
\hline 140 & 861.0211 & 20 & 0.8610 & 4.71300 \\
\hline 160 & 861.0813 & 20 & 0.8611 & 3.96932 \\
\hline 180 & 861.1368 & 20 & 0.8611 & 3.96901 \\
\hline 200 & 861.2062 & 20 & 0.8612 & 5.46032 \\
\hline 220 & 861.2617 & 20 & 0.8613 & 4.21594 \\
\hline 240 & 861.3126 & 20 & 0.8613 & 5.45926 \\
\hline 250 & 861.3033 & 20 & 0.8613 & 5.20565 \\
\hline 260 & 861.2848 & 20 & 0.8613 & 2.97665 \\
\hline 270 & 861.8168 & 20 & 0.8618 & 4.46741 \\
\hline
\end{tabular}

\section{Salient features of a heavy oil}

This section reviews the most significant physical properties of foamy oil flow including: compressibility, viscosity, surface tension, capillary number foam and foam stability.

\section{A. Compressibility}

Compressibility it's a non-equilibrium fluid property and the compressibility of the oil and gas dispersion is greater than solution gas [13]. Few studies carried out research studies to estimate compressibility of foamy oil. As per Kumar and Mahadevan [14], with known foamy oil properties, Foamy oil compressibility can affect pressure responses considerably.

\section{B. Viscosity}

Parallel solution gas drive experiments were conducted with a heavy crude oil from reservoir and a de-asphalted version of the

\section{E. Foamy oil Mechanism}

The whole process leading to the formation of a gas-in-oil dispersion: Supersaturation, critical supersaturation, Bubble nucleation, Bubble growth, and Bubble movement, or bubble migration

$S=P e-P$

Where: S- Supersaturation, Pe-Equilibrium Pressure, and PSystem Pressure

$$
J(t)=A \cdot \exp \left(\frac{-B}{\Delta P_{s}}\right)
$$

Where: J(t) Nucleation Rate, A \& B Constants, and $\Delta \mathrm{Ps}-$ Super Pressure difference. same oil and to eliminate the influence of oil viscosity, the original crude oil was diluted with a 50-50 mixture of heptane and toluene to reduce the viscosity to the same level as that of the deasphalted oil. The experiments were carried out in a visual sand pack that permitted observation of the bubble formation in the sand. The results show that the effect of asphaltene content varies with the depletion rate. At higher depletion rates, the oil recovery and production profile of crude oil with asphaltene is different from those without asphaltenes [15].

The values of apparent viscosity inferred from applications of classical solution-gas drive models to match the production performance are broadly less than that of those with gas behavior [16]. No exploratory check of this component has been accounted for so far in open writing. However, colloidal properties of asphaltenes and pitches have been the subject of extreme verbal confrontation in the writing. Moreover the substance of asphaltene is one of the principle criteria for the procedure control and the technique to move these oils will relies upon oil properties that incorporate thickness, API gravity, asphaltene content, what's more its capability to yield high esteem items after the refining procedure $[17,18]$. The noticeable components that are contemplated by Abusahmin et al. [19] involved refined mineral oil versus raw petroleum frameworks, the parameters incorporate; immersion weight, weight exhaustion rate, and weight drawdown. Both mineral and unrefined petroleum frameworks showed comparable decrease in the oil recuperation execution with diminishing rate of weight consumption [20].

\section{Capillary Number}

Many researchers have proposed different definitions for capillary number that all represent the ratio. The value of the capillary forces is a function of interfacial tension between the two phases as well as the pore geometry and the wettability conditions.

Often, the capillary number is expressed as:

$$
\mathrm{N}_{\mathrm{ca}}=\frac{\mathrm{k}}{\sigma \mathrm{dP}}
$$

Where $\sigma$ - the interfacial tension between the wetting and nonwetting fluid, " $\mathrm{k}$ " is the absolute permeability and $(\mathrm{dP} / \mathrm{dx})$ is the pressure gradient.

\section{Determination of fluid properties}

Two types of oil systems named crude oil saturated gas and artificial oil saturated gas were used along in the determination of fluid properties at various saturation pressures, these properties include compressibility as shown in Table 1 .

$G(t)=(\omega+v) \cdot K \cdot\left[s^{w}(t)\right] t^{(\omega+v-1)}$

Where: G-Growth Rate, K-Kinetic Constant, and $\omega, v$ - Positive Constants and t-Time 


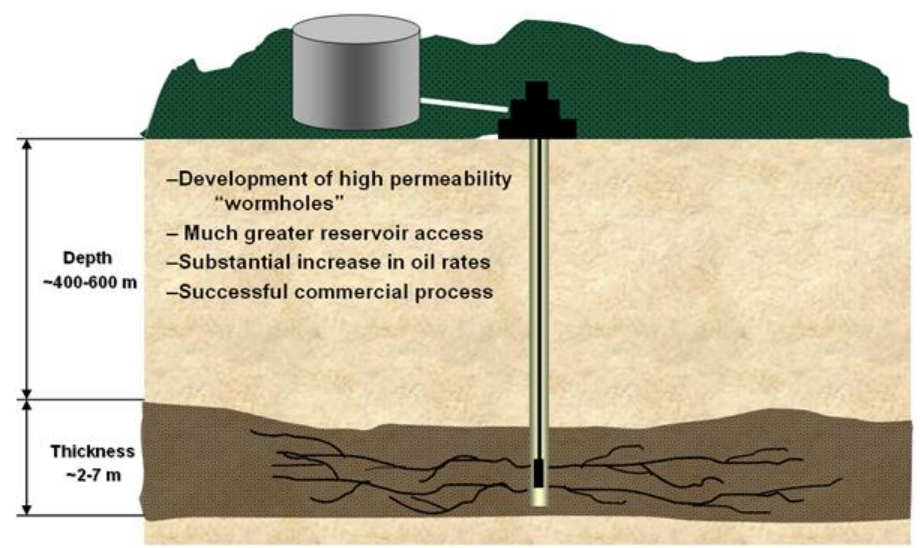

Fig. 2. Cold production Schematic.

\section{Results and discussions}

These experimentally found data were plotted on a P- $\rho$ graph, where the slope of the least square fitted line was used to calculate the compressibility. The plots for P- $\rho$ for mineral and the crude oil compressibility data are depicted in Figure's 3 and 4 respectively. Crude oil from Grimbek field in Argentina was found slightly compressible than the Catenex, mineral oil used and that is may contain some asphaltene content.

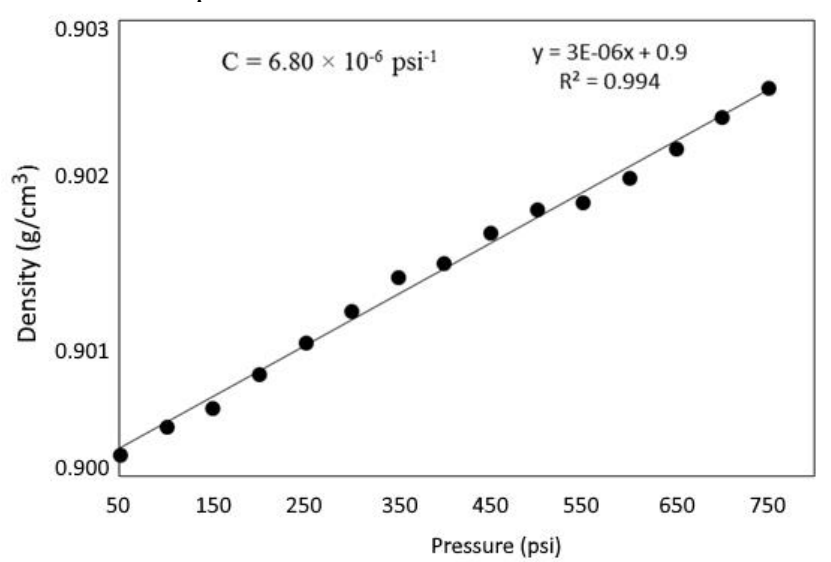

Fig. 3. Refined mineral oil compressibility curve at room temperature, 25degree $\mathrm{C}$

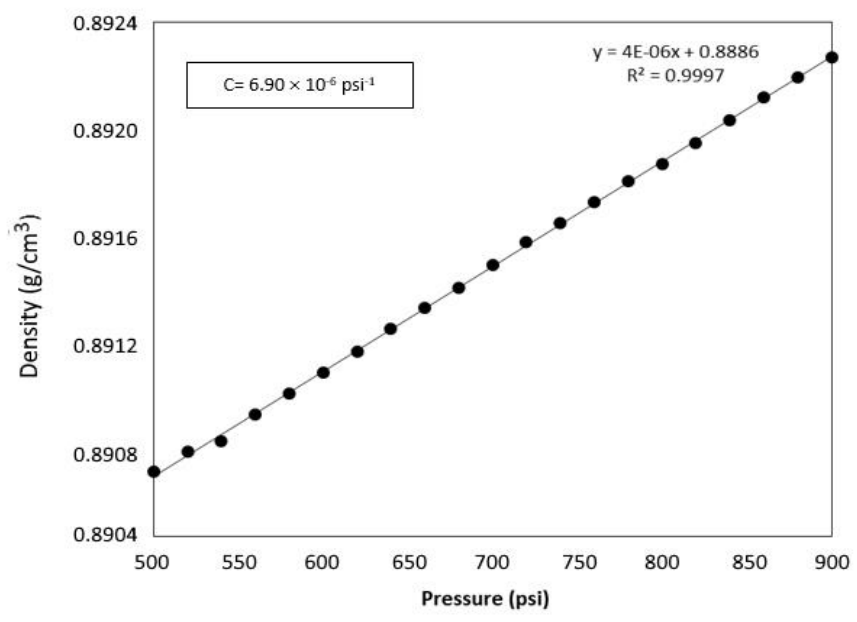

Fig. 4. Crude oil compressibility curve at room temperature at 25-degree $\mathrm{C}$

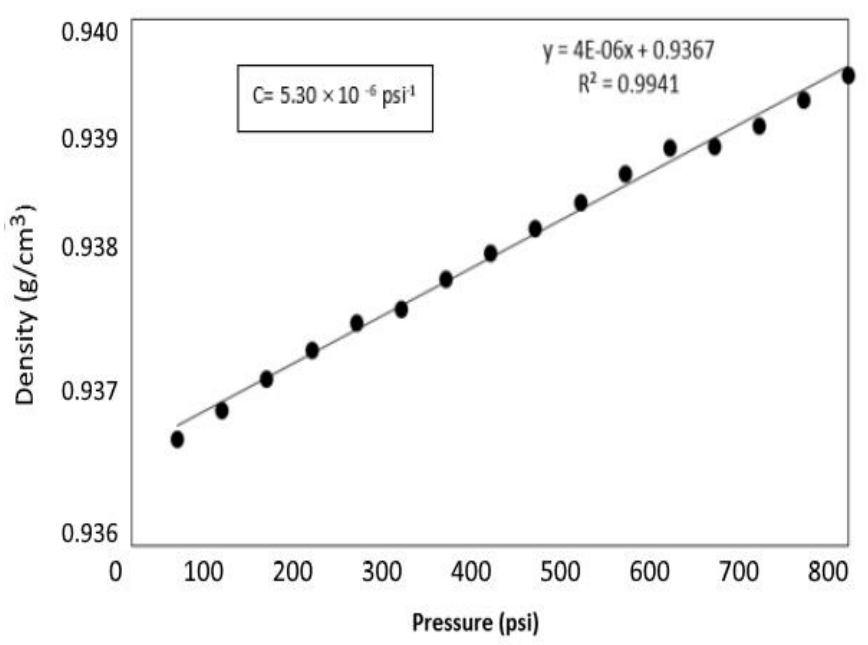

Fig. 5. Methane gas saturated mineral oil compressibility data at room temperature

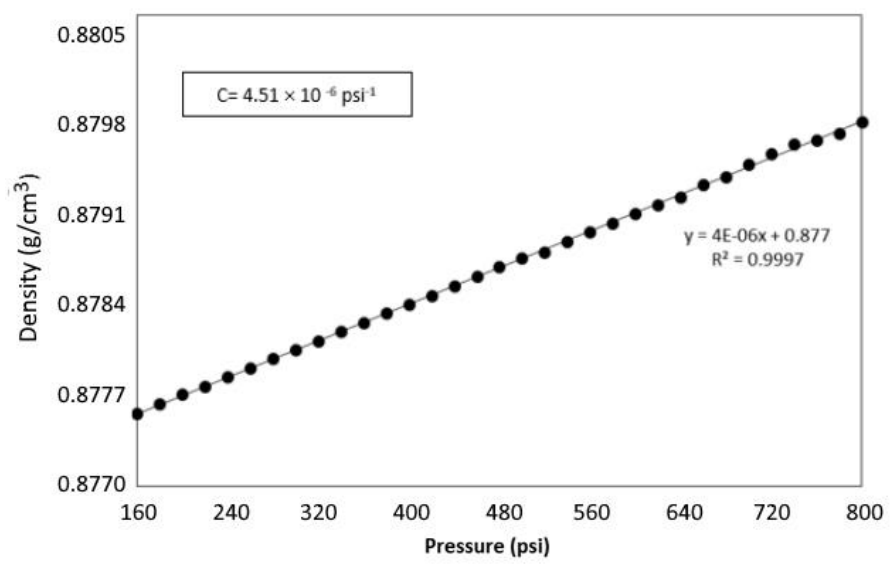

Figure 6 Carbon dioxide gas saturated mineral oil compressibility data at room temperature

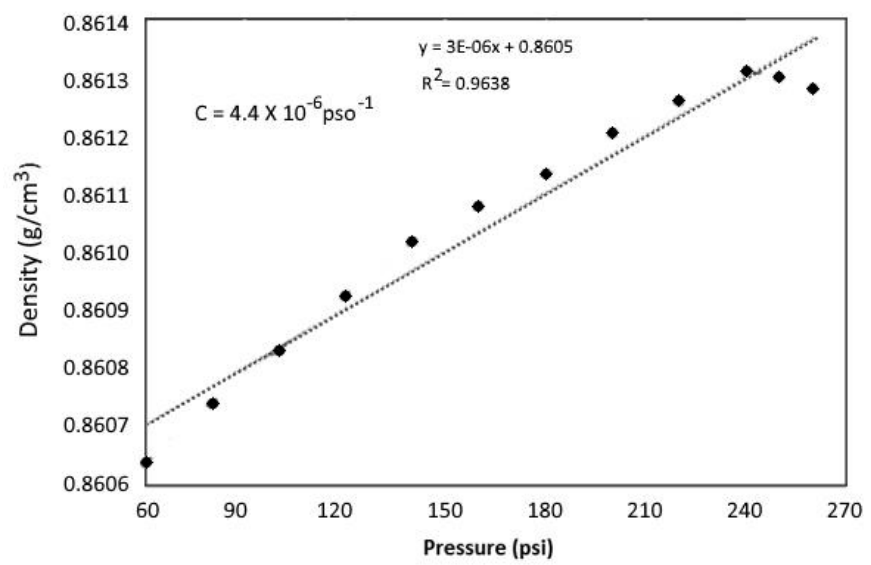

Fig. 7. Ethane saturated mineral oil compressibility data below the saturation pressure, $270 \mathrm{psi}$ at room temperature 


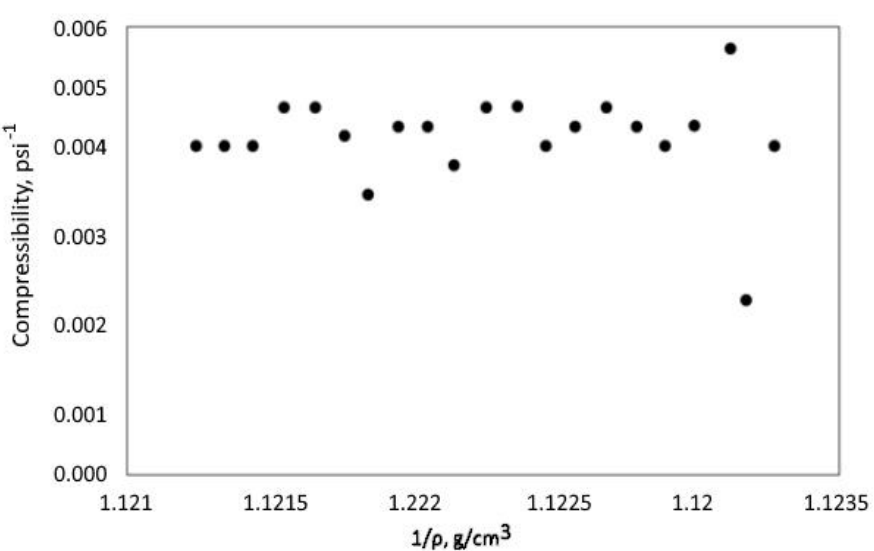

Fig. 8. Compressibility vs density using methane saturated mineral oil

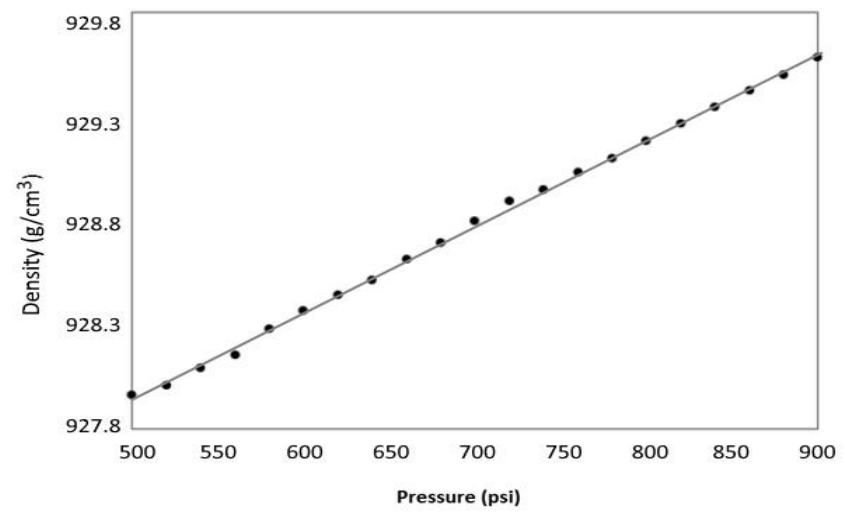

Fig. 9. Pressure and density profiles using methane-saturated crude oil

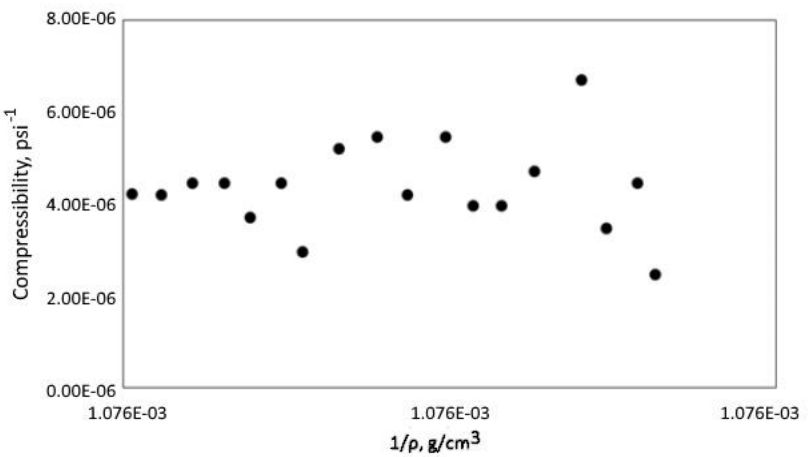

Fig. 10. Compressibility vs density using methane saturated crude oil

Figure's 5 and 6 represents the pressure, density history for methane saturated mineral gas system, carbon dioxide saturated mineral system and the trends, and variation follows the expected behaviour at the saturation pressures. Foamy oil compressibility maybe influenced by pressure reaction considerably related to density and prevailing pressure conditions. The trend of pressure versus density below the saturation pressure is depicted in Figure 7. The compressibility using ethane system is the highest among other gases, due to the gas nucleation and the nature of ethane gas, which can lead to a variation in saturation pressure, made a difference in performance. Figures 8 and 9 presents Compressibility as a function of density utilizing $\mathrm{CH} 4$ saturated mineral and crude oil at the same conditions. Figure 10 depicts the pressure history and density profiles using methane-saturated crude oil.

\section{Conclusions}

In this study, the pressure for methane and carbon dioxide was kept at the same pressure conditions whereas for ethane it was kept at 270 psi. The compressibility data for ethane-oil system looks much better than for methane oil system, and that is because of gas behavior in the oil system. The trend fits the expected behaviour at the saturation pressure. Non-Darcy form of two-phase flow behavior possibly will be more compressible. The flow of Non-Darcy form of two-phase behavior appears different from the traditional reservoirs. Asphaltene content did not have much impact to Non-Darcy form of two-phase behavior compressibility. Both systems demonstrated comparable results in the compressibility performance at the same saturation pressure as a function of density and pressure.

\section{References}

[1] B.S. Busahmin \& B.B. Maini (2011),Comparison between Foamy mineral oil and crude Oil under Solution - gas drive, in: Oil and gas conference, Calgary, Alberta, Canada.

[2] L. Xiao \& G. Zhao (2013), Integrated Study of Foamy Oil Flow and Wormhole Structure in CHOPS through Transient Pressure Analysis, in: SPE Heavy Oil Conference-Canada, Society of Petroleum Engineers.

[3] K.R. Rao, D.P. Rao, C. Venkateswarlu (2009), Soft sensor based nonlinear control of a chaotic reactor, IFAC Proceedings Volumes, 42, 537-543.

[4] R.R. Karri, J.N. Sahu (2018), Modeling and optimization by particle swarm embedded neural network for adsorption of zinc (II) by palm kernel shell based activated carbon from aqueous environment, Journal of Environmental Management, 206, 178-191.

[5] R.R. Karri, J.N. Sahu, N.S. Jayakumar (2017), Optimal isotherm parameters for phenol adsorption from aqueous solutions onto coconut shell based activated carbon: Error analysis of linear and non-linear methods, Journal of the Taiwan Institute of Chemical Engineers, 80 , 472-487.

[6] K.R. Rao, T. Srinivasan, C. Venkateswarlu (2010), Mathematical and kinetic modeling of biofilm reactor based on ant colony optimization, Process Biochemistry, 45,961-972.

[7] B. Busahmin, B. Maini, R.R. Karri, M. Sabet (2017), Studies on the Stability of the Foamy Oil in Developing Heavy Oil Reservoirs, Defect and Diffusion Forum, 371,111-116.

[8] J.G. Sheng, B.B. Maini, W.S. Tortike (1995), A Non-Equilibrium Model to Calculate Foamy Oil Properties, in: Annual Technical Meeting, Petroleum Society of Canada.

[9] B.B. Maini \& B. Busahmin (2010), Foamy oil flow and its role in heavy oil production, in: AIP Conference Proceedings, AIP, 103-108.

[10] X. Zhang, X. Wu, J. Zhang, R. Wang, L. Wang, R. Zhao, K. Liu (2012), A New Modeling Approach for Bubble Growth in Foamy Oil, Petroleum Science and Technology, 30, 1498-1507.

[11] B. Busahmin, B. Maini, U.H.B.H. Hasan (2017), Influence of Compressibility on Heavy/FoamyOil Flow, IOSR Journal of Engineering, 07, 18-28.

[12] M. Tavallali, B.B. Maini, T.G. Harding, B.S. Busahmin 2012, Assessment of SAGD Well Configuration Optimization in Lloydminster Heavy Oil Reserve, in: SPE/EAGE European Unconventional Resources Conference and Exhibition, Society of Petroleum Engineers.

[13] Hemmati-Sarapardeh, A. and Mohagheghian, E., Modeling interfacial tension and minimum miscibility pressure in paraffin-nitrogen systems: Application to gas injection processes. Fuel, Vol. 205 No., (2017), 80-89.

[14] Y. Shi, X. Li, D. Yang (2016), Nonequilibrium Phase Behavior of Alkane Solvent(s) -CO2-Heavy Oil Systems under Reservoir Conditions, Industrial \& Engineering Chemistry Research, 55, 28602871.

[15] R. Kumar, J. Mahadevan (2012), Well-performance relationships in heavy-foamy-oil reservoirs, SPE Production \& Operations, 27, 94105. 
[16] X. Sun, Y. Zhang, S. Wang, Z. Song, P. Li, C. Wang (2018) Experimental study and new three-dimensional kinetic modeling of foamy solution-gas drive processes, Scientific reports, 8, 4369.

[17] G.E. Smith, Fluid Flow and Sand Production in Heavy-Oil Reservoirs Under Solution-Gas Drive, SPE Production Engineering, 3 (1988) 169-180.

[18] E.L. Claridge (1994), A proposed model and mechanism for anomalous foamy heavy oil behavior.

[19] R.G. Santos, W. Loh, A.C. Bannwart, O.V. Trevisan (2014), An overview of heavy oil properties and its recovery and transportation methods, Brazilian Journal of Chemical Engineering, 31, 571-590.

[20] B.S. Abusahmin, R.R. Karri, B.B. Maini (2017), Influence of fluid and operating parameters on the recovery factors and gas oil ratio in high viscous reservoirs under foamy solution gas drive, Fuel, 197, 497-517.

[21] B. Busahmin, E.-S.M. Zahran, B. Maini (2016), Application of Foamy Mineral Oil Flow under Solution Gas Drive toa Field Crude Oil, The International Journal of Engineering and Science (IJES), 5, 48-58. 